\title{
Study on Initiation Mechanisms of Peresters Using $\alpha$-Methylstyrene Dimer (MSD) Trapping Technique
}

\author{
Yasumasa Watanabe, ${ }^{\dagger}$ Hideyo Ishigaki, Hiroshi OKada, \\ and Shuji SuYama \\ Fine Chemicals \& Polymers Research Laboratory, NOF Corporation, \\ Taketoyo-cho, Chita-gun, Aichi 470-23, Japan
}

(Received January 9, 1997)

\begin{abstract}
The thermal decomposition of $t$-butyl peroxybenzoate (2a) and $t$-butyl peroxylaurate (2b) was carried out in 2,4-diphenyl-4-methyl-1-pentene ( $\alpha$-methylstyrene dimer, MSD) at $140^{\circ} \mathrm{C}$. Free radicals generated from the peresters were efficiently trapped by MSD through the addition-fragmentation reaction. Benzoyloxy radicals generated from 2a underwent two competitive reactions, i.e., addition to MSD (71\%) and decarboxylation (29\%). On the other hand, decarboxylation was the sole reaction for lauroyloxy radicals from $\mathbf{2 b}$. For $t$-butoxy radicals, both results from $\mathbf{2 a}$ and $\mathbf{2 b}$ were identical, the ratio of addition to $\mathrm{MSD} / \beta$-scission being $61 / 39$. In the case of $\mathbf{2 b}$, the efficiency of free radical production was significantly lowered by cage reactions.

KEY WORDS Radical Trapping / Peresters / Initiation Mechanism / $\alpha$-Methylstyrene Dimer / Addition-Fragmentation /
\end{abstract}

Most commercial vinyl polymers such as polystyrene, polyethylene, and poly(vinyl chloride) are produced by free radical polymerization, where organic peroxides are used as main free radical initiators. Organic peroxides decompose thermally by homolytic cleavage of $\mathrm{O}-\mathrm{O}$ bond to give free radicals which initiate the polymerization of vinyl monomers. Thus, initiating radicals from organic peroxides are necessarily incorporated into polymer structure as end groups. Since such end groups are dependent on peroxide structure and have profound influence on polymer properties such as thermal and light stability, it is quite important to clarify the initiation mechanisms of organic peroxides, in particular, for commercially useful peroxides.

Several methods for investigating the initiation mechanisms of free radical initiators have been developed: a tracer technique using ${ }^{14} \mathrm{C}$ labeled initiators (Bevington et al. $\left.{ }^{1-3}\right),{ }^{13} \mathrm{C}$ NMR technique using ${ }^{13} \mathrm{C}$ labeled initiators (Bevington et al. ${ }^{4}$ and Moad et al., ${ }^{5}$ ), and nitroxide trapping technique (Rizzardo and Solomon ${ }^{6}$ ). These methods have provided useful information on reactions of radicals such as benzoyloxy and $t$-butoxy radicals with vinyl monomers such as styrene and methyl methacrylate. However, these data were mainly taken at specific temperature or do not cover a wide temperature range, in particular, with little information at high temperatures above $100^{\circ} \mathrm{C}$.

Quite recently, we have developed a new method for investigating the free radical chemistry of organic peroxides using 2,4-diphenyl-4-methyl-1-pentene ( $\alpha$-methylstyrene dimer, MSD) as a radical trapping agent and presented the initiation mechanisms of dialkyl peroxides at $140^{\circ} \mathrm{C} .{ }^{7}$ This original technique (MSD trapping technique) is based on a unique radical chemistry of MSD, that is, addition-fragmentation reaction between free radicals and MSD (eq 1 and 2). ${ }^{8}$ The easy deactivation of cumyl radicals by self-reactions (eq 3) also contributes to this success.

\footnotetext{
${ }^{\dagger}$ To whom all correspondence should be addressed.
}

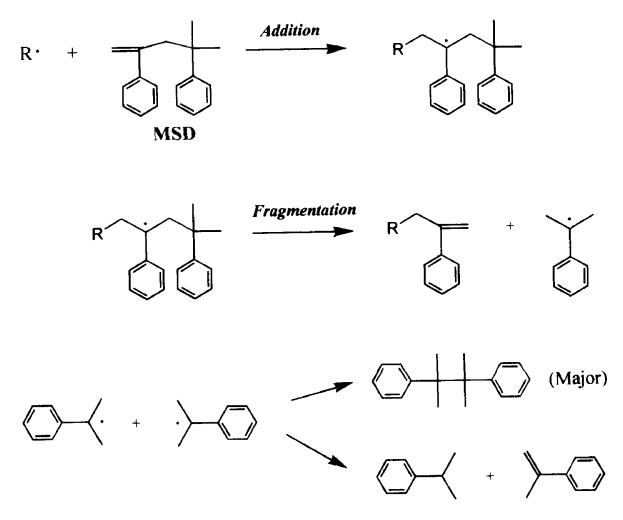

The outline of MSD trapping technique is depicted in Scheme 1. When organic peroxides decompose in MSD, olefinic compounds (1) having various fragments (X) derived from organic peroxides are produced through addition-fragmentation reaction. When MSD is present in large excess, the secondary reaction of $\mathbf{1}$ is negligible. By analyzing these trapping products (1), we can obtain useful information on the free radical chemistry of organic peroxides. In the earlier study, ${ }^{7}$ we have demonstrated that the double bond reactivity of MSD is about the same as that of styrene. Therefore, the trapping products are closely related to initiating radicals in styrene polymerization. In addition to its convenience, this technique has an advantage in that reactions can be carried out even at high temperatures above $100^{\circ} \mathrm{C}$.

$t$-Butyl peroxybenzoate (2a) and $t$-butyl peroxylaurate (2b) are popular initiators for commercial styrene polymerization and used at relatively high temperatures above $100^{\circ} \mathrm{C}$. So far, much attention has been paid to kinetics of their thermal decomposition and their performance for polymerization of vinyl monomers. However, detailed pictures concerning the initiation mechanisms of these peresters under such high temperature have not been presented. Bartlett and Hiatt ${ }^{9}$ and Pryor et al. ${ }^{10}$ showed that these peresters decompose by a onebond homolysis mechanism (not concertedly) to give two types of oxygen-centered radicals, acyloxy and $t$ - 
butoxy radicals. Since these oxygen-centered radicals undergo self-decomposition such as decarboxylation or $\beta$-scission in competition with addition to monomers, the initiation mechanisms of these peresters are quite complicated.

It is well known that the rates of decarboxylation of acyloxy radicals are greatly dependent on the structure, that is, the stability of carbon-centered radicals produced after decarboxylation. ${ }^{11}$ For example, the rate constants for decarboxylation of aroyloxy radicals such as benzoyloxy radicals are reported to be $c a .10^{6} \mathrm{~s}^{-1}$ at $c a$. $20^{\circ} \mathrm{C},{ }^{11,12}$ while those of alkanoyloxy radicals such as acetoxy and propionyloxy radicals are reported to be $10^{9}-10^{10} \mathrm{~s}^{-1}$ at $\mathrm{ca} .20^{\circ} \mathrm{C} .{ }^{11,13}$ Thus, it is interesting to compare the difference in initiation mechanisms between aromatic type of $\mathbf{2 a}$ and aliphatic type of $\mathbf{2} \mathbf{b}$.

This paper describes the results of a study on the initiation mechanisms of peresters (2) using MSD trapping technique at $140^{\circ} \mathrm{C}$. The results show clear pictures on their initiation mechanisms in styrene polymerization, including cage reaction processes of $\mathbf{2 b}$.

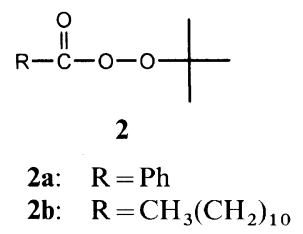

\section{EXPERIMENTAL}

\section{Measurements}

GLC analyses were performed with Shimadzu GC-14A and GC-17A gas chromatographs with a flame ionization detector using capillary columns $(15 \mathrm{~m} \times 0.53 \mathrm{~mm}$ or $25 \mathrm{~m} \times 0.25 \mathrm{~mm}$ ). GC-MS analysis was conducted on a Shimadzu QP5000 under electron impact conditions $(70 \mathrm{eV})$.

\section{Materials}

2,4-Diphenyl-4-methyl-1-pentene (MSD) was obtained from NOF Corporation (Nofmer MSD) and used after purifying by distillation. $t$-Butyl peroxybenzoate (2a) and $t$-butyl peroxylaurate (2b) were obtained from NOF Corporation and used as received. The purities of $\mathbf{2 a}$ and 2b were $98.6 \%$ and $98.2 \%$, respectively.

\section{MSD Trapping Experiments}

An aliquot $(2 \mathrm{ml})$ of $0.02 \mathrm{M}$ solution of peresters (2) in MSD was charged into a glass ampoule. The ampoule was purged with nitrogen, sealed, and immersed in a constant temperature bath regulated at $140^{\circ} \mathrm{C}$ for $5 \mathrm{~h}$. The reaction products were analyzed by GLC and GC-MS. Typical conditions of GLC analysis were as follows: column, $0.25 \mathrm{~mm} \times 25 \mathrm{~m}$ capillary column of silicon OV-1 (Shimadzu, HR-1); injector temperature, $150^{\circ} \mathrm{C}$; detector temperature, $250^{\circ} \mathrm{C}$; initial oven temperature, $50^{\circ} \mathrm{C}$; initial hold, $10 \mathrm{~min}$; program rate $1,10^{\circ} \mathrm{C}$ $\min ^{-1}$; middle oven temperature, $150^{\circ} \mathrm{C}$; middle hold,

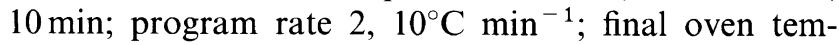
perature, $250^{\circ} \mathrm{C}$; final hold, $10 \mathrm{~min}$; carrier gas, $\mathrm{He}(0.4$ $\mathrm{ml} \mathrm{min}^{-1}$ ); split ratio, $1: 18$.

GC retention times and MS spectra of trapping products are given below. GC retention times were consistent with the molecular weights of trapping products, and all MS spectra showed parent peaks and characteristic fragment peaks of $117,103,91$, and 77 due to the 2-phenylallyl group of MSD.

3-Benzoyloxy-2-phenyl-1-propene (1a). GC retention time, $43.0 \mathrm{~min}$; $\mathrm{MS}(70 \mathrm{eV}) \mathrm{m} / z 238\left(\mathrm{M}^{+}\right), 117,115,105$, $103,91,77,65$, and 51.

2,3-Diphenyl-1-propene (1b). GC retention time, 36.6 $\min ; \operatorname{MS}(70 \mathrm{eV}) \mathrm{m} / z 194\left(\mathrm{M}^{+}\right), 179,165,117,116,115$, $103,91,77,65$, and 51.

3-t-Butoxy-2-phenyl-1-propene (1c). GC retention time, $27.9 \mathrm{~min} ; \mathrm{MS}(70 \mathrm{eV}) \mathrm{m} / z 190\left(\mathrm{M}^{+}\right), 175,145,134,117$, 103, 92, 91, 77, 57, and 41 .

2-Phenyl-1-butene (1d). GC retention time, $18.9 \mathrm{~min}$; $\operatorname{MS}(70 \mathrm{eV}) m / z 132\left(\mathrm{M}^{+}\right), 117,103,91,77,54$, and 51.

2-Phenyl-1-tetradecene (1e). GC retention time, 45.3 $\min ; \mathrm{MS}(70 \mathrm{eV}) \mathrm{m} / z 272\left(\mathrm{M}^{+}\right), 257,175,159,145,131$, $118,117,105,103,91,78,77,55$, and 41 .

\section{RESULTS AND DISCUSSION}

\section{Results of MSD Trapping}

The thermal decomposition of peresters (2) was carried out in MSD at $140^{\circ} \mathrm{C}$ for $5 \mathrm{~h}$ under nitrogen. The percentage of decomposition of 2 was over $99.9 \%$. The main reaction products, identified by GLC and GC-MS analysis, were trapping products (1) and dicumyl. For example, in the case of $\mathbf{2 a}$, the yield of dicumyl was as high as $95 \%$. Cumene and $\alpha$-methylstyrene were confirmed as minor products. The production of these compounds having the 2-phenylallyl or cumyl moiety of MSD showed the expected addition-fragmentation reaction between $\mathrm{MSD}$ and free radicals generated from peroxides to occur smoothly under the present reaction conditions.

Possible schemes leading to the production of $\mathbf{1}$ are shown in Schemes 2 and 3, including GLC yields of 1 based on total radicals produced theoretically from peroxides ( $2 \mathrm{~mol}$ of radicals per mol of 2 ). Total yields of trapping products were $81 \%$ for $\mathbf{2 a}$ and $45 \%$ for $\mathbf{2 b}$. The low recovery for $\mathbf{2 b}$ is mainly due to cage reactions (see below). It is seen from Scheme 2 that the total yield of alkoxy moiety $(36 \%)$ is somewhat lower than that of acyloxy moiety $(45 \%)$. This can be attributed to a side reaction caused by hydrogen abstraction by $t$-butoxy radicals $(t-\mathrm{BuO} \cdot)$, since the formation of $t$-butyl alcohol (ca. 10\%) was confirmed by GLC analysis. The most likely reaction is allylic hydrogen abstraction by $t$ - $\mathrm{BuO}$. from MSD (eq 4), since allylic hydrogens are known to

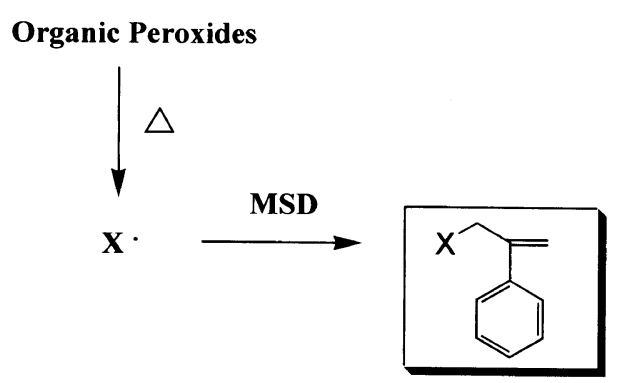

(1)

Scheme 1. Outline of MSD trapping. 


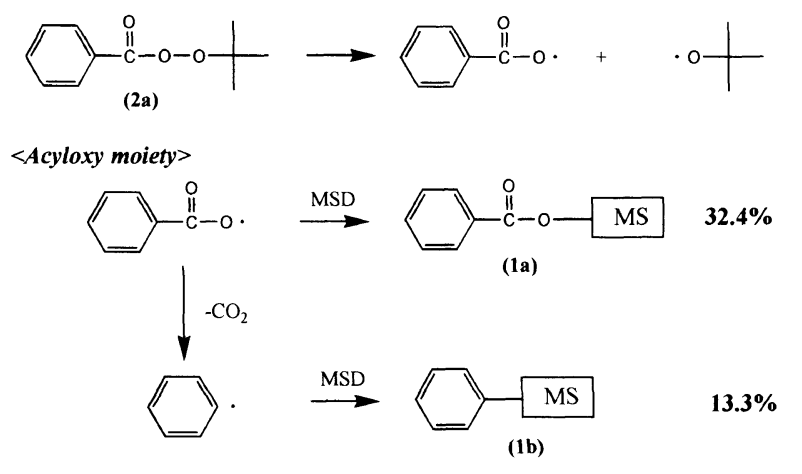

$<$ Alkoxy moiety $>$

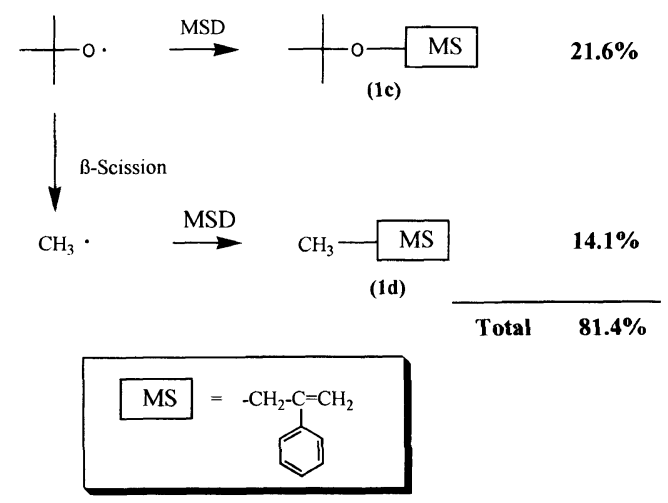

Scheme 2. Initiation mechanism of $2 \mathbf{a}$ at $140^{\circ} \mathrm{C}$.
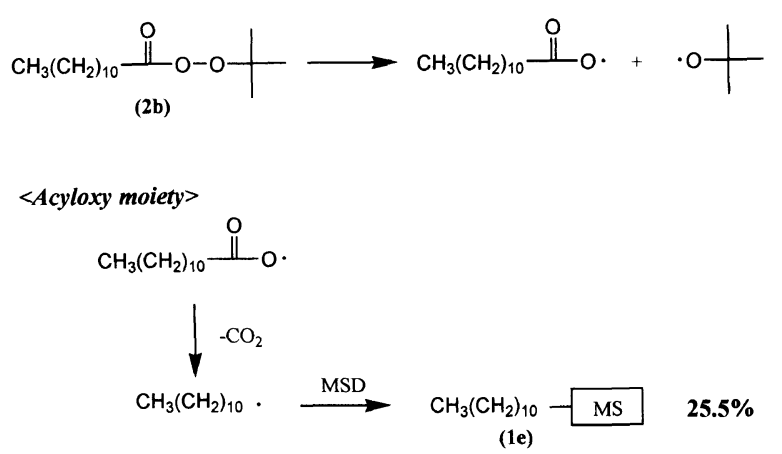

$<$ Alkoxy moiety $>$

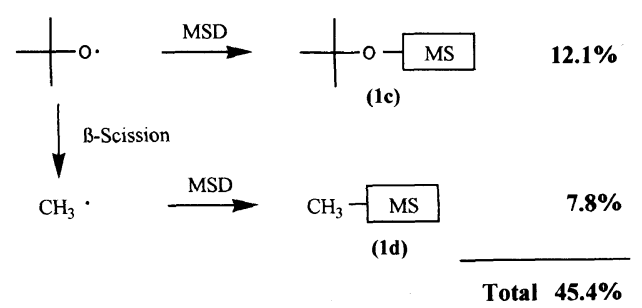

Scheme 3. Initiation mechanism of $2 \mathbf{b}$ at $140^{\circ} \mathrm{C}$.

be easily abstractable by $t$ - $\mathrm{BuO} \cdot$. For example, it was reported that the reaction of $t$-BuO with $\alpha$-methylstyrene at $60^{\circ} \mathrm{C}$ leads to $15 \%$ hydrogen abstraction from allylic hydrogenes ( $85 \%$ addition to the double bond). ${ }^{14}$

$$
+\mathrm{O}+\mathrm{T} \rightarrow \mathrm{H}_{\mathrm{OH}}+
$$

\section{Reactions of Acyloxy Radicals}

It is noted that benzoyloxy radicals ( $\mathrm{PhCOO} \cdot$ ) undergo two competitive reactions, i.e., addition to MSD and

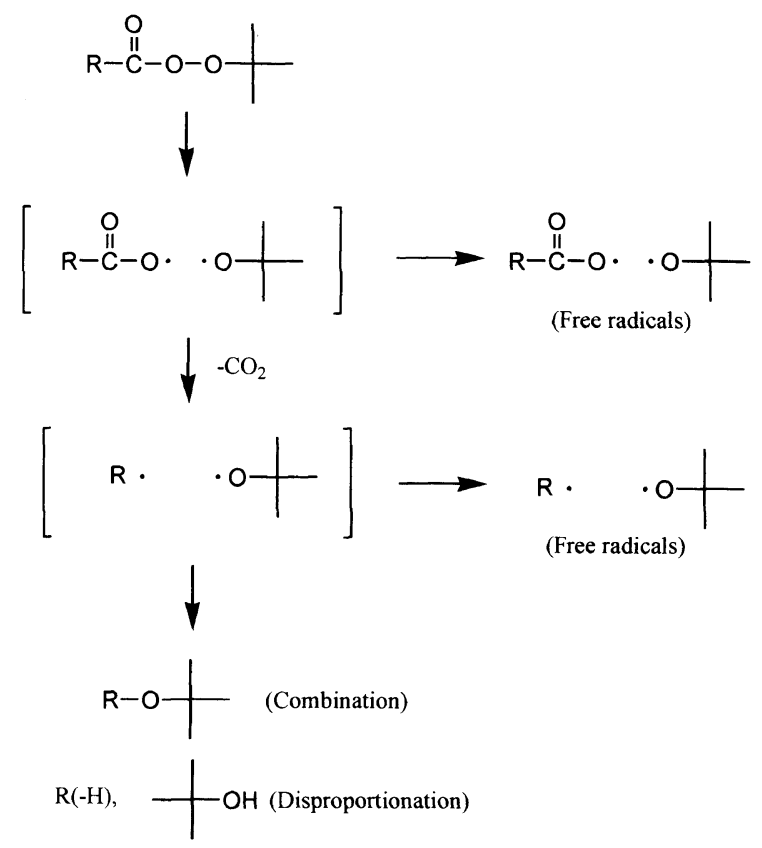

Scheme 4. Cage reaction processes of peresters.

decarboxylation, whereas decarboxylation is the sole reaction for lauroyloxy radicals. This difference can be reasonably explained in terms of much differences in decarboxylation rates. It is well known that the rates of decarboxylation of acyloxy radicals are greatly dependent on the structure, that is, the stability of carbon-centered radicals produced after decarboxylation. ${ }^{11}$ For example, the rate constants for decarboxylation of aroyloxy radicals such as benzoyloxy radicals are reported to be ca. $10^{6} \mathrm{~s}^{-1}$ at $c a .20^{\circ} \mathrm{C},{ }^{11,12}$ while those of alkanoyloxy radicals such as acetoxy and propionyloxy radicals are reported to be $10^{9}-10^{10} \mathrm{~s}^{-1}$ at $\mathrm{ca} .20^{\circ} \mathrm{C} .{ }^{11,13}$ Since lauroyloxy radicals are alkanoyloxy type, it is quite reasonable that lauroyloxy radicals decarboxylate much faster than $\mathrm{PhCOO}$ - and the acyloxy trapping product for $\mathbf{2 b}$ could not be observed.

Allen and Bevington ${ }^{1,2}$ reported relative rates of addition of $\mathrm{PhCOO}$ to styrene $\left(k_{\mathrm{a}}\right)$ and decarboxylation of $\mathrm{PhCOO} \cdot\left(k_{\mathrm{d}}\right)$ using ${ }^{14} \mathrm{C}$ tracer technique. $k_{\mathrm{a}} / k_{\mathrm{d}}$ ratios at 60 and $80^{\circ} \mathrm{C}$ were reported to be $2.5 \mathrm{M}^{-1}$ and $1.43 \mathrm{M}^{-1}$, respectively. Using these data, the $k_{\mathrm{a}} / k_{\mathrm{d}}$ ratio at $140^{\circ} \mathrm{C}$ was estimated to be $0.37 \mathrm{M}^{-1}$ according to the conventional Arrhenius equation. Thus, when styrene concentration is kept at $4.2 \mathrm{M}$, the ratio of $\mathrm{PhCOO}$. addition to styrene relative to decarboxylation should be $61 / 39$. In this study $\left(140^{\circ} \mathrm{C},[\mathrm{MSD}]=4.2 \mathrm{M}\right)$, it was $71 / 29$. It seems that the accuracy of the predicted value is not so high due to extrapolation to a high temperature from only two data. However, fairly good agreement between our result for MSD and the predicted value for styrene strongly support that the double bond reactivity of MSD towards $\mathrm{PhCOO}$. is about the same as that of styrene.

\section{Cage Reaction}

As mentioned above, the total yield of trapping products for $\mathbf{2 b}$ was not so high $(45 \%)$. It is well known that the efficiency of production of free radicals from aliphatic peresters is significantly lowered due to cage 
reaction processes ${ }^{15}$ depicted in Scheme 4. Decarboxylation of aliphatic peresters occurs very fast, so some radical pairs $(\mathrm{R} \cdot$ and $t$ - $\mathrm{BuO} \cdot)$ still remain in a solvent cage and react with each other to give ethers as combination products or olefins and alcohols as disproportionation products. Therefore, the main reason for the low radical recovery for $\mathbf{2 a}$ should be due to this cage reaction. To demonstrate it, we checked cage reaction products. We could confirm the production of $t$-butyl undecyl ether and 1-undecene, and the GLC yields based on $\mathbf{2 b}$ were $37 \%$ and $8 \%$, respectively. This indicates that free radical efficiency of $\mathbf{2 b}$ is $55 \%$. The total radical trapping yield for $\mathbf{2 b}(45 \%)$ is somewhat lower than this value. This is because of a side reaction of $t-\mathrm{BuO} \cdot$, i.e., hydrogen abstraction from MSD mentioned above. It is well known that alkyl radicals are much poor hydrogen abstractors. For example, Carrock and Szwarc ${ }^{16}$ reported that the rate of addition of methyl radicals to styrene is about 800 times larger than that of hydrogen abstraction by methyl radicals from isooctane at $65^{\circ} \mathrm{C}$. Therefore, it is reasonable to assume that undecyl radicals produced from $\mathbf{2 b}$ add to MSD quantitatively and free radical efficiency of $\mathbf{2 b}$ is double the yield of $\mathbf{1 e}$ (i.e., $51 \%$ ). This estimation is in fairy good agreement with that from cage products analysis.

\section{Summary}

The distribution of reactions of acyloxy radicals and $t$ - $\mathrm{BuO} \cdot$ is summarized in Table $\mathrm{I}$. PhCOO undergoes two competitive reactions, i.e., addition (71\%) and decarboxylation $(29 \%)$. In contrast, lauroyloxy radicals undergo $100 \%$ decarboxylation. It is interesting to compare the reactivity of $t-\mathrm{BuO} \cdot$ generated from different

Table I. Distribution of reactions of radicals in $\mathrm{MSD}$ at $140^{\circ} \mathrm{C}^{\mathrm{a}}$

\begin{tabular}{lccc}
\hline \multicolumn{1}{c}{ Radical } & Source & Addition $/ \%$ & Scission $^{\mathrm{b}} / \%$ \\
\hline $\mathrm{PhCOO}$ & $\mathbf{2 a}$ & 71 & 29 \\
$\mathrm{CH}_{3}\left(\mathrm{CH}_{2}\right)_{10} \mathrm{COO}$. & $\mathbf{2 b}$ & 0 & 100 \\
$t-\mathrm{BuO} \cdot$ & $\mathbf{2 a}$ & 61 & 39 \\
$t-\mathrm{BuO}$ & $\mathbf{2 b}$ & 61 & 39 \\
$t-\mathrm{BuO}$ & $\mathrm{DTBP}$ & $62^{\mathrm{d}}$ & $38^{\mathrm{d}}$
\end{tabular}

a Initial peroxide concentration, $0.02 \mathrm{M}$; MSD concentration, $4.2 \mathrm{M}$. ${ }^{\mathrm{b}} \beta$-Scission for alkoxy radicals and decarboxylation for acyloxy radicals. ${ }^{\mathrm{c}}$ Di- $t$-butyl peroxide. ${ }^{\mathrm{d}}$ Data from ref 7 . sources. As seen in Table I, the results among three different cases agreed very well. This indicates that the reactivity of radicals is kept unchanged even though different radical sources are used.

In conclusion, MSD trapping technique has been successfully applied to investigation into the initiation mechanisms of peresters and provided clear mechanistic pictures at $140^{\circ} \mathrm{C}$ for commercially useful peresters. This study also shows that MSD trapping is useful for determining the initiator efficiency of organic peroxides. The detailed study on initiator efficiency of various free radical initiators is currently underway.

\section{REFERENCES}

1. J. C. Bevington, Proc. Roy. Soc., A, 239, 420 (1957).

2. J. C. Bevington and J. Toole, J. Polym. Sci., 28, 413 (1958).

3. J. K. Allen and J. C. Bevington, Proc. Roy. Soc., A, 262, 271 (1961).

4. J. C. Bevington, J. R. Ebdon, T. N. Huckerby, and N. W. E. Hutton, Polymer, 23, 163 (1982).

5. G. Moad, D. H. Solomon, S. R. Johns, and R. I. Willing, Macromolecules, 15, 1188 (1982).

6. E. Rizzardo and D. H. Solomon, Polym. Bull., 1, 529 (1979); P. G. Griffiths, E. Rizzardo, and D. H. Solomon, J. Macromol. Sci. Chem., A17, 45 (1982); P. G. Griffiths, E. Rizzardo, and D. H. Solomon, Tetrahedron Lett., 23, 1309 (1982); G. Moad, E. Rizzardo, and D. H. Solomon, J. Macromol. Sci. Chem., A17, 51 (1982); G. Moad, E. Rizzardo, and D. H. Solomon, Macromol. Chem., Rapid Commun., 3, 533 (1982); G. Moad, E. Rizzardo, and D. H. Solomon, Macromolecules, 15, 909 (1982).

7. Y. Watanabe, H. Ishigaki, H. Okada, and S. Suyama, Polym. J., 29, 366 (1997).

8. Y. Watanabe, H. Ishigaki, H. Okada, and S. Suyama, Chem. Lett., 1089 (1993); S. Suyama, H. Ishigaki, Y. Watanabe, and T.Nakamura, Polym. J., 27, 371 (1995); S. Suyama, H. Ishigaki, Y. Watanabe, and T. Nakamura, Polym. J., 27, 503 (1995).

9. P. D. Bartlett and R. R. Hiatt, J. Am. Chem. Soc., 80, 1398 (1958).

10. W. A. Pryor, E. H. Morkved, and H. T. Bickley, J. Org. Chem., 37, 1999 (1972).

11. K. Fujimori, in "Organic Peroxides," W. Ando, Ed., John Wiley \& Sons, New York, N.Y., 1992, pp 361-367.

12. J. Chateauneuf, J. Lusztyk, and K. U. Ingold, J. Am. Chem. Soc., 110, 2886 (1988).

13. E. A. Turetskaya, E. D. Skakorskii, S. V. Rikov, Yu. V. Glazkov, and Yu. A. Ol'dekop, Dokl. Akad. Nauk. U.S.S.R., 24, 57 (1980); Chem. Abstr., 92-197682 (1980).

14. R. D. Grant, E. Rizzardo, and D. H. Solomon, Makromol. Chem., 185, 1809 (1984).

15. R. A. Sheldon and J. K. Kochi, J. Am. Chem. Soc., 92, 5175 (1970).

16. F. Carrock and M. Szwarc, J. Am. Chem. Soc., 81, 4138 (1959). 